\title{
Espacios convencionales de los derechos políticos en las sentencias de la Corte Interamericana a través de un sistema semiautomático de inteligencia artificial*
}

\section{Conventional Spaces of Political Rights} in the Judgments of the Inter-American Court through a Semiautomatic System of Artificial Intelligence

Espaces conventionnels de droits politiques dans les jugements de la Cour interaméricaine à travers un système semiautomatique d'intelligence artificielle

\author{
Jesús E. Sanabria-Moyano** \\ W. Ricardo Rodríguez-Beltrán $\mathbf{n}^{* * *}$ \\ R. E. Gutiérrez-Carvajal ${ }^{*+* t+}$
}

SUMARIO: I. Introducción. II. Método de análisis jurisprudencial. III. Los derechos políticos en la jurisprudencia de la Corte Interamericana. IV. Conclusiones. V. Bibliografía.

* Este artículo es producto del proyecto POS_DER_3267, “Detección automática de espacios convencionales de la Corte Interamericana para la identificación de estándares de protección en derechos humanos", financiado por la Vicerrectoría de Investigaciones de la Universidad Militar Nueva Granada, vigencia 2020-2021.

** Universidad Militar Nueva Granada, Colombia; ORCID ID: https://orcid.org/0000-00 01-9715-5305, jesus.sanabria@unimilitar.edu.co.

*** Universidad Militar Nueva Granada, Colombia; ORCID ID: https://orcid.org/0000-00 03-2798-2123.

**** Universidad Militar Nueva Granada, Colombia; ORCID ID: https: / /orcid.org/0000-00 02-6013-5463.

Artículo recibido el 3 de diciembre de 2019 Aprobado para publicación el 9 de octubre de 2020 
ResUmen: Los derechos políticos son una garantía fundamental en la Convención Americana sobre Derechos Humanos, por lo cual el presente artículo busca dar respuesta a la siguiente pregunta: ¿cuáles son los estándares convencionales de los derechos políticos en la Corte Interamericana? Para ello se hizo aplicación de un sistema semiautomático de búsqueda de jurisprudencia de este tribunal interamericano, en el marco del uso de la analítica de datos aplicada al método de análisis jurisprudencial. El uso de esta herramienta permitió identificar los espacios convencionales que la Corte Interamericana ha desarrollado en su jurisprudencia respecto de los derechos políticos, como son: a) el derecho a ser elegido; b) el derecho a la igualdad de oportunidades en el acceso y la estabilidad en cargos públicos; c) el derecho a participar en asuntos públicos, y d) las limitaciones a los derechos políticos.

Palabras clave: Convención Americana, Corte Interamericana, derechos políticos, inteligencia artificial, espacios convencionales.

ABSTRACT: Political rights are a fundamental guarantee in the American Convention on Human Rights; therefore, this article seeks to answer the following question: What are the conventional standards of political rights in the Inter-American Court? Applied a semi-automatic system for searching jurisprudence of this Inter-American Court, within the framework of the use of data analytics applied to the jurisprudential analysis method. The use of this tool allowed identifying the conventional spaces that the Inter-American Court has developed in it is jurisprudence regarding political rights, such as: $a$ ) the right to be elected; $b$ ) the right to equal opportunities in access and stability in public office; c) the right to participate in public affairs, and d) limitations on political rights.

Key words: American Convention, Inter-American Court, political rights, artificial intelligence, conventional spaces.

RÉSUMÉ: Les droits politiques sont une garantie fondamentale dans la Convention américaine relative aux droits de l'homme; par conséquent, cet article cherche à répondre à la question suivante: Quelles sont les normes conventionnelles des droits politiques à la Cour interaméricaine? A appliqué un système semi-automatique pour recherche de la jurisprudence de cette Cour interaméricaine, dans le cadre de l'utilisation de l'analyse de données appliquée à la méthode d'analyse jurisprudentielle. L'utilisation de cet outil a permis d'identifier les espaces conventionnels que la Cour interaméricaine y a développés est la jurisprudence relative aux droits politiques, tels que: a) le droit d'être élu; b) le droit à l'égalité des chances en matière d'accès et de stabilité dans la fonction publique; c) le droit de participer aux affaires publiques, et d) limitations des droits politiques.

Mots-clés: Convention américaine, Cour interaméricaine, droits politiques, intelligence artificielle, espaces conventionnels. 


\section{INTRODUCCIÓN}

La jurisprudencia emitida por la Corte Interamericana permite identificar los parámetros de interpretación de la Convención Americana sobre Derechos Humanos; esto crea la aplicación por parte de la Corte Interamericana de un sistema de precedentes judiciales, dando seguridad jurídica al sistema interamericano y a los Estados parte del mismo. Además, estos precedentes generan la creación de estándares de protección de derechos humanos (DDHH), que deben ser aplicables por todos los Estados mediante el control de convencionalidad, con el fin de cumplir las obligaciones emanadas de la Convención. ${ }^{1}$

Por tanto, las sentencias de la Corte Interamericana se caracterizan por desarrollar extensos análisis entre los derechos humanos reconocidos por el tratado y el cumplimiento o no de las obligaciones convencionales del Estado, lo cual genera que en una misma sentencia se presenten por un mismo hecho la correlación de diferentes derechos violados y, de paso, la conexidad con las obligaciones, a fin de determinar si el Estado es responsable o no. En este análisis hermenéutico, la Corte Interamericana identifica el precedente relevante que se relaciona analógicamente con el caso bajo estudio y los incluye en los considerandos de cada uno de los derechos o del grupo de derechos humanos analizados, por lo cual se puede identificar que el método de trabajo que realiza este órgano surge a partir de la construcción de líneas temáticas que pueden considerarse líneas jurisprudenciales. ${ }^{2}$

En este orden de ideas, para la creación de una línea jurisprudencial se debe iniciar con la formulación de un problema jurídico por resolver a través de la jurisprudencia de un determinado órgano judicial ${ }^{3}$ dicho problema puede surgir de un espacio en la norma que, al ser interpretado por el órgano judicial, permite identificar unos parámetros o estándares. Ello implica

1 González, Andrés y Sanabria, Jesús, “Obligaciones de los Estados parte de la Convención Americana”, Saber, Ciencia y Libertad, Colombia, vol. 8, núm. 2, 2013, pp. 45-56.

2 Hitters, Juan Carlos, “¿Son vinculantes los pronunciamientos de la Comisión y de la Corte Interamericana de Derechos Humanos? (control de constitucionalidad y convencionalidad)", Revista Iberoamericana de Derecho Procesal Constitucional, México, vol. 10, 2008, pp. 131-156.

3 López Medina, Diego, El derecho de los jueces: obligatoriedad del precedente constitucional, análisis de sentencias y líneas jurisprudenciales y teoría del derecho judicial, 2a. ed., Bogotá, Legis, 2006, p. 366. 
hacer un rastreo de las decisiones que se relacionan con el problema jurídico planteado, y a partir de su lectura y análisis identificar si dan respuesta de forma directa o simplemente dan elementos que permiten identificar una posible respuesta a la situación que se plantea. A partir de ello, se podrían clasificar las sentencias seleccionadas entre sentencias hito, fundadora de línea, confirmadora de principio y arquimédica. ${ }^{4}$

Con esta técnica se pueden identificar algunos espacios convencionales, que en la práctica son el desarrollo interpretativo del alcance del derecho humano reconocido en la Convención Americana y, con ello, la creación de estándares de protección, los cuales se encuentran obligados a cumplir los Estados que se someten a la jurisdicción de la Corte Interamericana. ${ }^{5}$

Sin embargo, en la práctica, identificar estos espacios convencionales es un trabajo dispendioso para los investigadores, los jueces y los litigantes del sistema interamericano de derechos humanos; por ello, el uso de herramientas tecnológicas contribuye a detectar más rápido y de mejor forma las sentencias que permiten describir los espacios convencionales, lo cual es mucho más efectivo en el momento de crear documentos jurídicos que requieran soportes jurisprudenciales con precedentes de la Corte Interamericana. Por tanto, el objetivo es aplicar un sistema de búsqueda y navegación semiautomática, a fin de identificar los espacios convencionales de los derechos políticos establecidos por la Corte Interamericana y, con ello, establecer cuáles son los estándares y obligaciones por cumplir de los Estados parte de la Convención Americana.

Para dar cumplimiento a dicho objetivo, los grupos de investigación en derecho público de la Facultad de Derecho y "Acceder" de la Facultad de Ingeniería de la Universidad Militar Nueva Granada han creado un sistema de inteligencia artificial para el análisis semiautomático de la jurisprudencia de la Corte Interamericana, con el que se identifican espacios citacionales, los cuales se encuentran representados a través de grafos, cuya lectura e interpretación permiten establecer estándares jurisprudenciales de los derechos reconocidos en la Convención Americana, con el fin simplificar la labor de creación de futuras sentencias, memoriales por parte de abogados litigantes en el sistema interamericano y el desarrollo de trabajos académicos y de investigación.

4 Idem.

5 García Ramírez, Sergio, "El control judicial interno de convencionalidad”, Revista IUS, Chile, vol. 5, núm. 28, 2011, pp. 123-159. 
Ahora bien, con el mencionado navegador y respondiendo al interés de aplicar dicha herramienta, se realizó el estudio de los derechos políticos en la Corte Interamericana, teniendo en cuenta que, de acuerdo con la revisión bibliográfica realizada, hasta el momento no se ha llevado a cabo un estudio que se apoye en el uso de inteligencia artificial en busca de espacios convencionales de algún derecho establecido en la Convención Americana. Por esta razón, el problema jurídico que se plantea en esta investigación es el siguiente: ¿cuáles son los estándares convencionales de los derechos políticos emitidos por la Corte Interamericana? Para dar respuesta a esta pregunta, se desarrolló una herramienta computacional que modela el flujo de trabajo de los operadores jurídicos, permitiendo el rastreo de decisiones relacionadas con el problema legal en el dominio jurisprudencial de la Corte Interamericana. Las sentencias relacionadas con el derecho político se representaron como un grafo no dirigido, cuyas relaciones representaban las citaciones entre las distintas decisiones. Una vez modelada esta estructura, la herramienta permite al usuario reconocer las sentencias hito, fundadoras de línea, confirmadoras y arquimédicas, las cuales se resaltan mediante la aplicación de teoría de grafos en este dominio, particularmente las métricas de centralidad del grafo y técnicas de agrupamiento automático.

Por último, la metodología empleada en esta investigación es multidisciplinaria, ya que parte de un problema eminentemente jurídico que requiere la aplicación del método de análisis jurisprudencial, pero también se emplea un método de trabajo de las ciencias computacionales, que en el presente caso es el análisis de datos, con el cual se permite el desarrollo de una inteligencia artificial que grafica los espacios citacionales a partir de las conexiones en las sentencias de la Corte Interamericana en las que desarrolla los derechos políticos. Posterior a ello, el usuario de la herramienta hace una lectura e interpretación del grafo diseñado por la herramienta e identifica los diferentes espacios convencionales que integran el derecho, a fin de dar respuesta al problema de investigación.

En el desarrollo del objetivo y la metodología planteada, se expondrá, en primer lugar, las generalidades del método de análisis jurisprudencial; posteriormente, se explicará cómo se aplica el sistema de navegación semiautomático, haciendo uso de esta técnica frente a los derechos políticos; luego, se analizará los espacios convencionales obtenidos, y, finalmente, se darán paso a las conclusiones. 


\section{MÉTODO DE ANÁLISIS JURISPRUDENCIAL}

Con respecto al método de creación de espacios citacionales y los espacios convencionales, es importante analizar el precedente judicial. Para ello, se debe hacer mención que en el mundo jurídico existen cinco grandes familias jurídicas: romano-germánica, common law, socialista, religiosa, los sistemas híbridos y mixtos. ${ }^{6}$ Sin embargo, en el mundo occidental se aplican sólo dos: la familia romano-germánica y el common law.

Frente a estas dos familias jurídicas, es evidente que tienen una matriz cultural similar y, desde un estudio dinámico de estos sistemas, es posible distinguirlos de otras familias jurídicas a través de la identificación de los diferentes órganos que promulgan su conjunto de normas, así como de la fuerza vinculante y las consecuencias que trae para los sujetos su incumplimiento. Precisamente, estos aspectos dependen del uso de fuentes de derecho, que les permiten expresarse y alcanzar su obligatoriedad. ${ }^{7}$

A pesar de que las fuentes de derecho en estas dos familias jurídicas son idénticas, como son la ley, la costumbre, los tratados internacionales y la jurisprudencia, es muy diferente su uso y fuerza vinculante de cada fuente de acuerdo con la familia jurídica. Por ejemplo, el sistema de common law tiene como fuente principal la jurisprudencia ${ }^{8}$ cuya autoridad se deriva de la regla de obligatoriedad del precedente que establecen los tribunales frente a la resolución de litigios; ${ }^{9}$ por ello, se da prevalencia al derecho judicial. ${ }^{10}$ Por otro lado, la fuente principal del sistema romano-germánico es la ley y la obligatoriedad se la concede la rama legislativa, que puede estar representada en congreso o consejo, dependiendo de cada Estado.

6 Pérez Perdomo, Rogelio, “González Martín, Nuria, Sistemas jurídicos contemporáneos, México, Nostra Ediciones-UNAM, Instituto de Investigaciones Jurídicas, 2010”, Boletín Mexicano de Derecho Comparado, México, vol. XLVI, núm. 136, 2013, pp. 403-405.

7 Noguera Laborde, Rodrigo, Introducción general al derecho, Bogotá, Universidad Sergio Arboleda, 2015, p. 338.

8 Blasco Gascó, Francisco de Paula, "Funciones y eficacia de la norma jurisprudencial”, Estudios de Derecho Judicial, España, núm. 34, 2001, pp. 185-236.

9 Whittaker, Simon y Banfi del Río, Cristian, "El precedente en el derecho inglés: una visión desde la ciudadela”, Revista Chilena de Derecho, Chile, vol. 35, núm. 1, 2008, pp. 37-83.

10 López Medina, Diego, op. cit. 
De esta forma, a partir del uso del derecho comparado como el estudio de las familias jurídicas y sus sistemas, ${ }^{11}$ se evidencia que la aplicación del precedente judicial no ha sido ajena para ninguno de los sistemas jurídicos. Incluso, en el derecho internacional se identifica cierta similitud con los sistemas jurídicos nacionales, ${ }^{12}$ pero se adaptan a las necesidades de las instituciones que resuelven los problemas de relevancia mundial. Con relación a las fuentes, el Estatuto de la Corte Internacional de Justicia determina en su artículo 38 las fuentes del derecho internacional:

....a. las convenciones internacionales, sean generales o particulares, que establecen reglas expresamente reconocidas por los Estados litigantes; b) la costumbre internacional como prueba de una práctica generalmente aceptada como derecho; c) los principios generales de derecho reconocidos por las naciones civilizadas; d) las decisiones judiciales y las doctrinas de los publicistas de mayor competencia de las distintas naciones, como medio auxiliar para la determinación de las reglas de derecho (cursivas añadidas).

Asimismo, en el artículo 59 señala que las sentencias, para las partes del conflicto, sí tienen fuerza normativa. A partir de ello, se destaca que la jurisprudencia de los órganos judiciales internacionales ha tomado más relevancia en los últimos años, pues a través de la interpretación y la aplicación de los tratados ${ }^{13}$ y la costumbre internacional en las decisiones judiciales se desarrolla el derecho internacional. ${ }^{14}$ De esta forma, la relevancia del precedente se evidencia en que, para decidir, los tribunales referencian decisiones previas, justificando por qué la regla es correcta, equivocada o diferente e, incluso, vinculante en el caso concreto. ${ }^{15}$ Así, se comparte lo establecido por Benavides:

11 González, Andrés y Sanabria, Jesús, op. cit.

12 Toro Huerta, Mauricio Iván del, “Anatomía del precedente internacional (esbozo para la discusión)”, en Carbonell Sánchez, Miguel et al. (coords.), Estado constitucional, derechos humanos, justicia y vida universitaria. Estudios en homenaje a Jorge Carpizo, México, UNAM, Instituto de Investigaciones Jurídicas, 2015, t. III, pp. 75-107.

13 Fernández Fernández, Vicente, "La justicia de los precedentes: ¿invasión a la independencia y autonomía del juzgador?”, Revista de Derecho (Valdivia), Chile, vol. 29, núm. 2, pp. 9-33.

14 Jiménez de Aréchaga, Eduardo et al., Derecho internacional público: principios, normas y estructuras, Montevideo, Fundación de la Cultura Universitaria, 2005, t. 1, p. 511.

15 Cohen, Harlan Grant, "International Precedent and the Practice of International Law", en Helfand, Michael A. (ed.), Negotiating State and Non-State Law:The Challenge of Global and Local Legal Pluralism, Cambridge University Press, 2015, pp. 172-194. 
... las instancias de carácter judicial son necesarias tanto para el desarrollo del derecho internacional como para contar con otros mecanismos de cumplimiento de las obligaciones, más allá de las retorsiones y represalias. Una sentencia es una norma jurídica particular vinculante y obligatoria para el Estado parte del juicio. ${ }^{16}$

Particularmente, con relación al sistema interamericano de protección de derechos humanos, se establece en la Convención Americana que la Corte Interamericana es el órgano al cual le corresponde la interpretación y aplicación del tratado, mientras que los Estados parte se comprometen a cumplir sus decisiones, de tal forma que todos sus fallos deben ser motivados. ${ }^{17}$

Por ello, con respecto a la función jurisdiccional, la Corte Interamericana decide sobre la responsabilidad internacional de un Estado parte por el incumplimiento de las obligaciones frente a los derechos humanos, de conformidad con lo establecido en la Convención Americana sobre Derechos Humanos y otros pactos interamericanos que le reconocen competencia a la Corte Interamericana, así como de estándares de protección que ha fijado en casos análogos. En estas sentencias es posible identificar que existen argumentos con carácter de ratio decidendi, en los cuales se encuentran reglas de derecho que establece la Corte Interamericana para dar solución a un problema jurídico en concreto. Cuando estas reglas de derecho son reiteradas por la Corte Interamericana para resolver casos análogos, se está frente a estándares de protección que deben ser observados y acatados por los Estados.

Dentro de esta ratio decidendi, es posible encontrar cómo la Corte Interamericana define los derechos convencionales, así como los elementos que los integran y las relaciones que se establecen entre ellos frente a escenarios en particular. De igual forma, explica las obligaciones de respeto, garantía, adecuación y no discriminación que deben cumplir los Estados para evitar la vulneración de los derechos humanos, consagradas en los dos primeros artículos de la Convención Americana. ${ }^{18}$

16 Benavides-Casals, María Angélica, "El efecto erga omnes de las sentencias de la Corte Interamericana de Derechos Humanos", International Law: Revista Colombiana de Derecho Internacional, Colombia, núm. 27, 2015, pp. 141-166.

17 OEA, Convención Americana sobre Derechos Humanos (Pacto de San José), Costa Rica, 7-22 de noviembre de 1969, disponible en: https: / /www.oas.org/dil/esp/tratados_b-32_conven cion_americana_sobre_derechos_humanos.htm.

18 González, Andrés y Sanabria, Jesús, op. cit. 
Igualmente, en cumplimiento de la obligación de motivar los fallos, se identifica obiter dictum, en la cual la Corte Interamericana define elementos que no son indispensables para la decisión de responsabilidad, pero que sí permiten comprender la naturaleza del derecho humano o las obligaciones internacionales.

De esta forma, es posible evidenciar que dentro del sistema interamericano también existen precedentes fijados en la Corte Interamericana. En primer lugar, se trata de "autoprecedentes", puesto que es la misma Corte Interamericana quien fija determinado estándar de protección y en un caso análogo lo retoma, con el fin de explicar la responsabilidad o no del Estado. Asimismo, en ocasiones, dicho tribunal interamericano hace uso de precedentes horizontales, cuando en sus sentencias menciona argumentos establecidos por cortes de otros sistemas de protección de derechos humanos. Por último, también se evidencia una relación con los Estados parte, puesto que, en virtud de los principios de complementariedad y subsidiariedad, la Corte Interamericana en ocasiones estudia las sentencias emitidas por los tribunales internos de los Estados.

En cuanto a la obligatoriedad del precedente, se establece en el artículo 66 de la Convención Americana que "los Estados Parte en la Convención se comprometen a cumplir la decisión de la Corte en todo caso en que sean partes". A partir del estudio de este artículo, algunos doctrinantes desarrollaron la doctrina de res judicata, en virtud de la cual se afirma que el fallo exclusivamente es vinculante para el Estado sobre el cual la Corte Interamericana decidía su responsabilidad internacional. ${ }^{19}$ Sin embargo, con los posteriores pronunciamientos de la misma Corte Interamericana, se determinó que los postulados de la ratio decidendi tienen efectos erga omnes, por lo cual deben ser tenidos en cuenta por los demás Estados, quienes deben velar por que los efectos de las disposiciones de la Convención y la sentencia no se vean disminuidos por la aplicación de normas contrarias.

Esta doctrina es conocida como res interpretata y tiene relación directa con el control de convencionalidad que se establece en el sistema interamericano. En ella se explica que los Estados tienen la obligación de adecuar sus actuaciones a nivel interno, con el fin de que sean conformes tanto a los tratados como a la interpretación que realiza la Corte Interamericana sobre los instrumentos internacionales:

19 Quinche, Manuel, El precedente judicial y sus reglas, 2a. ed., Bogotá, Ediciones Doctrina y Ley, 2016, p. 208. 
Todas sus autoridades y todos sus órganos, incluidas las instancias democráticas, jueces y demás órganos vinculados a la administración de justicia en todos los niveles, están obligados por el tratado, por lo cual deben ejercer, en el marco de sus respectivas competencias y de las regulaciones procesales correspondientes, un control de convencionalidad tanto en la emisión y aplicación de normas, en cuanto a su validez y compatibilidad con la Convención, como en la determinación, juzgamiento y resolución de situaciones particulares y casos concretos, teniendo en cuenta el propio tratado y, según corresponda, los precedentes o lineamientos jurisprudenciales de la Corte Interamericana. ${ }^{20}$

De esta forma, a partir de las decisiones de la Corte Interamericana, se crean una serie de estándares de protección de derechos humanos que deben ser aplicables por todos los Estados sujetos a su jurisdicción, con el fin de cumplir las obligaciones emanadas de la Convención Americana y garantizar seguridad jurídica dentro del sistema. Es decir, la jurisprudencia de la Corte Interamericana no sólo es citada como ejercicio hermenéutico en la construcción de decisiones, sino también establece criterios que irradian a los Estados, con el objeto de dar cumplimiento a las obligaciones convencionales de respeto, garantía, adecuación y no discriminación en conexidad con los derechos humanos, al interior de su jurisdicción. ${ }^{21}$

De acuerdo con ello, es posible evidenciar que los precedentes desarrollados por la Corte Interamericana tienen fuerza vinculante para los Estados parte de la Convención Americana, de tal forma que se destaca su importancia como órgano de protección de derecho humanos en la región y su influencia en las decisiones que toman los tribunales de los Estados a nivel interno.

En vista de ello, una de las técnicas utilizadas para el estudio de un problema jurídico es el desarrollo de líneas jurisprudenciales, en virtud de las cuales se encuentran posibles respuestas de conformidad con la decisión adoptada por los jueces previamente. Para su construcción, el investigador debe tener en cuenta las sentencias que se relacionen directamente con el tema de estudio. Para ello, es útil hacer uso de los buscadores o identificar la sentencia más reciente y que los hechos sean relevantes o tengan el mismo patrón

20 Corte IDH, Serie C núm. 266, Caso de la Corte Suprema de Justicia (Quintana Coello y otros) vs. Ecuador. Sentencia del 23 de agosto de 2013. Excepción preliminar, fondo, reparaciones y costas.

21 González, Andrés y Sanabria, Jesús, op. cit. 
fáctico, pues ayudarán a identificar las demás sentencias que hablan sobre el tema. En la búsqueda, López Medina recomienda estudiar la denominada "sentencia arquimédica", caracterizada por ser reciente y contar con hechos relevantes con el mismo patrón fáctico.

El grupo de sentencias que encuentre el investigador relacionadas con su tema de estudio se denomina "espacios citacionales", pues se constituyen a partir de la relación de citas entre sí que desarrollan las sentencias cuyo contenido es de conformidad con el precedente fijado por el órgano judicial en relación con el tema de interés del investigador. Al interior de estos espacios citacionales, es posible identificar que el órgano judicial realiza la interpretación de los artículos de la normativa en diferentes situaciones y define sus elementos cuando entran en conflicto.

Para el caso de la Corte Interamericana, ello se denomina "espacios convencionales", realizando un símil con lo que López Medina denomina “escenario constitucional" y define como "zona de choque de intereses donde la Corte puede desplegar el análisis de la Constitución para encontrar balances que maximicen la protección de derecho. Entre todas estas zonas hay afinidades generales que se desprenden de elementos culturales, morales, políticos y económicos". ${ }^{22}$ Estos estándares convencionales, cuando colidan con otros derechos, pueden generar "subespacios" o "espacios convencionales de segundo nivel”.

Estos espacios o subespacios convencionales brindan herramientas al investigador para la formulación de su problema jurídico, definido por López Medina como la pregunta que encabeza la línea jurisprudencial y que el investigador intenta resolver mediante la interpretación dinámica de varios pronunciamientos judiciales, además de la relación de éstos con otros materiales normativos. Este problema debe ser concreto, con el propósito de dar respuesta de forma directa con las sentencias y dependerá de qué tipo de línea quiere desarrollar el investigador.

Para ello, como explica López Medina, el investigador debe tener en cuenta que existen diferentes tipos de sentencias, de las cuales debe preferir aquellas que gocen de lealtad argumentativa para conformar el precedente, tal y como se señala a continuación.

La primera de ellas se denomina "hito", donde se establece de forma general la regla de derecho en la sentencia. A su vez, esta sentencia puede asumir la forma de fundadora de línea, en la que, tratándose de una inicial,

22 López Medina, Diego, op. cit. 
goza de riqueza argumentativa; por ello, suele tener bastante obiter dictum. Por otro lado, puede ser una consolidadora de línea, en la cual, además de retomar la regla de derecho establecida, la define con más precisión. Otra forma es la modificadora, la cual incluye cambios fuertes a la regla derecho que resuelve el problema jurídico del caso en estudio. No obstante, cuando la sentencia introduce una teoría nueva o forma de interpretar, se trata de una reconceptualizadora; en cambio, si resuelve conflictos de interés, se define como una sentencia dominante.

Así las cosas, según explica López Medina, el investigador puede encontrar otro tipo de sentencias que no serán directamente relevantes para su estudio. Entre ellas se encuentra la confirmadora de principio, la cual desarrolla el deber de obediencia del precedente, aplicando la ratio decidendi. Por otro lado, se encuentran las sentencias confusas o inconcluyentes, que tienen poca ratio y no definen de forma clara la solución al problema jurídico, y, por último, tenemos a las que son en exceso abstractas, pues contienen poca ratio decidendi y mucha obiter dictum sin relación con el caso.

Una vez se realice, se graficará el problema y se ubicarán las sentencias según sea su respuesta. De esta forma, se podrá evidenciar si se identifica la existencia de balance convencional; es decir, si existe doctrina jurisprudencial vigente que sirve como regla de conducta y estándar de crítica ${ }^{23}$ y demás conclusiones según sus objetivos planteados.

Teniendo en cuenta lo anterior y con la utilización del sistema de inteligencia artificial, se construirá una línea de precedentes de la Corte Interamericana frente a los derechos políticos, y el sistema reflejará los espacios citacionales, con la relevancia que han tenido las distintas sentencias de la Corte Interamericana frente a los derechos políticos; luego, se evidenciarán los espacios convencionales y, posteriormente, se describirán los estándares convencionales.

\section{LOS DERECHOS POLÍTICOS EN LA JURISPRUDENCIA} DE LA CORTE INTERAMERICANA

Este capítulo se desarrollará con base en los precedentes establecidos por la Corte Interamericana frente a los derechos políticos, de acuerdo con las 23 Idem. 
sentencias establecidas por la inteligencia artificial conforme a la relevancia de cada sentencia y, de igual forma, al número de veces en el que son citadas. Posterior a ello, teniendo en cuenta la gráfica expuesta por la herramienta, se desarrollarán cuatro espacios convencionales, generando con ello los estándares de la Corte Interamericana frente a los derechos políticos.

\section{Descripción de los derechos políticos por parte} de la Corte Interamericana

Frente al contexto del sistema interamericano de protección de derechos humanos, la Convención Americana sobre Derechos Humanos consagra en su artículo 23 a los derechos políticos:

1. Todos los ciudadanos deben gozar de los siguientes derechos y oportunidades:

a) de participar en la dirección de los asuntos públicos, directamente o por medio de representantes libremente elegidos;

b) de votar y ser elegidos en elecciones periódicas auténticas, realizadas por sufragio universal e igual y por voto secreto que garantice la libre expresión de la voluntad de los electores, y

c) de tener acceso, en condiciones generales de igualdad, a las funciones públicas de su país.

2. La ley puede reglamentar el ejercicio de los derechos y oportunidades a que se refiere el inciso anterior, exclusivamente por razones de edad, nacionalidad, residencia, idioma, instrucción, capacidad civil o mental, o condena, por juez competente, en proceso penal. ${ }^{24}$

En la mayoría de las ocasiones en que se pronuncia por primera vez sobre un derecho convencional, la Corte Interamericana establece dentro de su sentencia algunos parámetros y definiciones conceptuales sobre tal derecho; estos parámetros y conceptualizaciones son retomadas por jurisprudencia sucesora, con miras a crear estándares de protección del derecho. Frente a los derechos políticos, se aprecian varias situaciones: en primer lugar, todas las personas tienen derecho a participar en la dirección de asuntos públicos; en segundo lugar, ellas cuentan con el derecho a elegir y ser elegidos en

24 OEA, Convención Americana sobre Derechos Humanos, cit. 
cargos públicos en condiciones de igualdad, y, en tercer lugar, frente a qué razones se puede limitar o restringir los derechos políticos.

Por consiguiente, la Corte Interamericana se ha pronunciado en 22 ocasiones, teniendo como el caso más citado el de Yatama vs. Nicaragua, mediante el cual se establece la importancia de los derechos políticos, pues mediante éstos "se propician el fortalecimiento de la democracia y el pluralismo político". ${ }^{25}$ De acuerdo con este carácter fundamental, la Corte Interamericana ha señalado:

...el ejercicio efectivo de los derechos políticos constituye un fin en sí mismo y, a la vez, un medio fundamental que las sociedades democráticas tienen para garantizar los demás derechos humanos previstos en la Convención, y que sus titulares, es decir, los ciudadanos, no sólo deben gozar de derechos, sino también de "oportunidades”. Este último término implica la obligación de garantizar con medidas positivas que toda persona que formalmente sea titular de derechos políticos tenga la oportunidad real para ejercerlos. ${ }^{26}$

Ahora bien, frente a la definición y el rango de aplicación de los derechos políticos, la Corte Interamericana, en casos como Castañeda Gutman vs. México y, más recientemente, Petro Urrego vs. Colombia, ha definido al artículo 23 de la Convención Americana sobre Derechos Humanos de la siguiente manera:

El artículo 23 contiene diversas normas que se refieren a los derechos de la persona como ciudadano, esto es, como titular del proceso de toma de decisiones en los asuntos públicos, como elector a través del voto o como servidor público, es decir, a ser elegido popularmente o mediante designación o nombramiento para ocupar un cargo público. Además de poseer la particularidad de tratarse de derechos reconocidos a los ciudadanos, a diferencia de casi todos los demás derechos previstos en la Convención que se reconocen a toda persona, el artículo 23 de la Convención, no solo establece que sus titulares deben gozar de derechos, sino que agrega el término “oportunidades". Esto último implica la obligación de garantizar con medidas positivas que toda persona que formalmente sea titular de derechos políticos tenga la

25 Corte IDH, Serie C núm. 127, Caso Yatama vs. Nicaragua. Sentencia del 23 de junio de 2005. Excepciones preliminares, fondo, reparaciones y costas, párr. 192.

26 Ibidem, párr. 191; Corte IDH, Serie C núm. 184, Caso Castañeda Gutman vs. México. Sentencia del 6 de agosto de 2008. Excepciones preliminares, fondo, reparaciones y costas, párr. 144; Corte IDH, Serie C núm. 233, Caso López Mendoza vs.Venezuela. Sentencia del 1o. de septiembre de 2011. Fondo, reparaciones y costas, párr. 108. 
Esta revista forma parte del acervo de la Biblioteca Jurídica Virtual del Instituto de Investigaciones Jurídicas de la UNAM

oportunidad real para ejercerlos. Como ya lo señalara este Tribunal anteriormente, es indispensable que el Estado genere las condiciones y mecanismos óptimos para que los derechos políticos puedan ser ejercidos de forma efectiva, respetando el principio de igualdad y no discriminación. ${ }^{27}$

A partir de esta interpretación, la Corte Interamericana ha venido estableciendo ciertas definiciones de los derechos que intrínsecamente forman parte de las garantías políticas, como el derecho a decidir en asuntos públicos, el derecho a ser elegido, el derecho a elegir y las limitaciones a los derechos políticos.

2. Nichos citacionales y espacios convencionales de los derechos políticos en la jurisprudencia de la Corte Interamericana

La Corte Interamericana ha seguido desarrollando estas definiciones en casos posteriores; además, ha establecido la aplicación y los estándares de los derechos políticos en 21 casos, que tienen autocitaciones por parte de la misma Corte Interamericana, creando los espacios citacionales. Frente a esto, la analítica de datos arroja el número de veces que una sentencia ha sido citada por la Corte Interamericana para abordar o desarrollar los derechos políticos.

\begin{tabular}{|c|c|}
\hline \multicolumn{2}{|c|}{ Ranking con número de citaciones $^{28}$} \\
\hline C 127 & 23 \\
\hline C 184 & 19 \\
\hline
\end{tabular}

27 Corte IDH, Serie C núm. 127, CasoYatama vs. Nicaragua, cit., párr. 194; Corte IDH, Serie C núm. 348, Caso San Miguel Sosa y otras vs.Venezuela. Sentencia del 8 de febrero de 2018. Fondo, reparaciones y costas, párr. 11.

28 El cuadro 1 es resultado de los datos generados por la inteligencia artificial, teniendo en cuenta los datos de 21 sentencias de la Corte Interamericana: Comunidad Mayagna (Sumo) Awas Tingni vs. Nicaragua; Carpio Nicolle y otros vs. Guatemala; Yatama vs. Nicaragua; Claude Reyes y otros vs. Chile; Escué Zapata vs. Colombia; Castañeda Gutman vs. México; Apitz Barbera y otros ("Corte Primera de lo Contencioso Administrativo") vs. Venezuela; Reverón Trujillo vs. Venezuela; Chitay Nech y otros vs. Guatemala; Manuel CepedaVargas vs. Colombia; Chocrón Chocrón vs.Venezuela; López Mendoza vs.Venezuela; Pueblo Indígena de Kichwa de Sarayaku vs. Ecuador; Corte Suprema de Justicia (Quintana Coello y otros) vs. Ecuador; Tribunal Constitucional (Camba Campos y otros) vs. Ecuador; Luna López vs. Honduras; Argüelles y otros vs. Argentina; López Lone y otros vs. Honduras; Pueblos Kaliña y Lokono vs. Surinam; Pacheco León y otros vs. Honduras; San Miguel Sosa y otras vs. Venezuela. 
Esta revista forma parte del acervo de la Biblioteca Jurídica Virtual del Instituto de Investigaciones Jurídicas de la UNAM

\begin{tabular}{|c|c|}
\hline \multicolumn{2}{|c|}{ Ranking con número de citaciones } \\
\hline C 266 & 11 \\
\hline C 302 & 11 \\
\hline C 348 & 11 \\
\hline C 268 & 10 \\
\hline C 227 & 9 \\
\hline C 269 & 9 \\
\hline C 197 & 8 \\
\hline C 342 & 8 \\
\hline C 212 & 7 \\
\hline C 213 & 7 \\
\hline C 233 & 7 \\
\hline C 182 & 6 \\
\hline C 288 & 5 \\
\hline C 79 & 1 \\
\hline C 245 & 1 \\
\hline C 309 & 1 \\
\hline C 117 & 0 \\
\hline C 151 & 0 \\
\hline C 165 & 0 \\
\hline
\end{tabular}

Para establecer la importancia de cada sentencia, por una parte, se cuenta el número de veces que es citada (véase cuadro 1) y, por otro lado, se estima la influencia que ha tenido cada sentencia en la Corte Interamericana mediante el análisis automático, que simula una caminata aleatoria en el espacio citacional; por lo tanto, se considerarán como sentencias más influyentes aquellas por las cuales un caminante aleatorio visitaría con mayor frecuencia. De acuerdo con ello, tenemos algunas sentencias que son más influyentes, como la del asunto C 127, caso Yatama vs. Nicaragua, que es la más importante frente a derechos políticos. Es así como mediante la inteligencia artificial se establece un score para determinar la importancia de la sentencia. 
Esta revista forma parte del acervo de la Biblioteca Jurídica Virtual del Instituto de Investigaciones Jurídicas de la UNAM

\begin{tabular}{|c|c|}
\hline \multicolumn{2}{|c|}{ Ranking por influencia ${ }^{29}$} \\
\hline C 127 & 52.99782729 \\
\hline C 184 & 42.5428122 \\
\hline C 269 & 30.43031659 \\
\hline C 302 & 29.16940142 \\
\hline C 342 & 27.46847625 \\
\hline C 213 & 27.46847613 \\
\hline C 348 & 25.93285527 \\
\hline C 233 & 22.38371612 \\
\hline C 288 & 22.38371612 \\
\hline C 197 & 22.36420645 \\
\hline C 212 & 19.65612795 \\
\hline C 182 & 17.16037025 \\
\hline C 266 & 14.21122267 \\
\hline C 268 & 14.21122267 \\
\hline C 227 & 12.47360863 \\
\hline C 309 & 9.583755619 \\
\hline C 79 & 0.1539471966 \\
\hline C 245 & 0.1539471966 \\
\hline C 117 & 0.04761904762 \\
\hline C 151 & 0.04761904762 \\
\hline C 165 & 0.04761904762 \\
\hline
\end{tabular}

Como se puede observar, el caso más citado y relevante en la Corte Interamericana, con respecto al artículo 23 de la Convención Americana sobre Derechos Humanos, es el C 127, conocido como caso Yatama vs. Nicaragua.

29 El cuadro 2 es resultado de los datos generados por la inteligencia artificial, tomando en consideración los datos de 21 sentencias de la Corte Interamericana: Comunidad Mayagna (Sumo) Awas Tingni vs. Nicaragua; Carpio Nicolle y otros vs. Guatemala; Yatama vs. Nicaragua; Claude Reyes y otros vs. Chile; Escué Zapata vs. Colombia; Castañeda Gutman vs. México; Apitz Barbera y otros (“Corte Primera de lo Contencioso Administrativo") vs. Venezuela; Reverón Trujillo vs. Venezuela; Chitay Nech y otros vs. Guatemala; Manuel Cepeda Vargas vs. Colombia; Chocrón Chocrón vs. Venezuela; López Mendoza vs. Venezuela; Pueblo Indígena de Kichwa de Sarayaku vs. Ecuador; Corte Suprema de Justicia (Quintana Coello y otros) vs. Ecuador; Tribunal Constitucional (Camba Campos y otros) vs. Ecuador; Luna López vs. Honduras; Argüelles y otros vs. Argentina; López Lone y otros vs. Honduras; Pueblos Kaliña y Lokono vs. Surinam; Pacheco León y otros vs. Honduras; San Miguel Sosa y otras vs.Venezuela. 
Éste se dio por la participación política de organizaciones indígenas conglomeradas con el nombre de Yatama, las cuales intentaron obtener la autorización y ser reconocidos como partido político; sin embargo, el Estado de Nicaragua negó dicha autorización y, con ello, las comunidades no pudieron participar activamente en las elecciones de 2000. Es así como este caso es el primero en el que la Corte Interamericana condena a un Estado por la violación de los derechos políticos.

De acuerdo con ello, se evidencia que el casoYatama vs. Nicaragua tiene 23 citaciones de sentencias posteriores. En esta sentencia se da inicio y desarrollo de los derechos políticos en la jurisprudencia de la Corte Interamericana, por lo cual se realiza la descripción de tales derechos, pero a su vez se establece cómo los Estados deben cumplir con las obligaciones de garantía y no discriminación. En dicha sentencia, la Corte señala lo siguiente:

La Corte entiende que, de conformidad con los artículos 23, 1.1 y 2 de la Convención, el Estado tiene la obligación de garantizar el goce de los derechos políticos, lo cual implica que la regulación del ejercicio de dichos derechos y su aplicación sean acordes al principio de igualdad y no discriminación, y debe adoptar las medidas necesarias para garantizar su pleno ejercicio. Dicha obligación de garantizar no se cumple con la sola expedición de normativa que reconozca formalmente dichos derechos, sino requiere que el Estado adopte las medidas necesarias para garantizar su pleno ejercicio, considerando la situación de debilidad o desvalimiento en que se encuentran los integrantes de ciertos sectores o grupos sociales. ${ }^{30}$

Con respecto a lo anterior, la Corte Interamericana establece que los Estados no simplemente están obligados a la creación de una norma, sino que deben adoptar medidas para garantizar el real y pleno goce de los derechos políticos con base en los principios de igualdad y no discriminación. Asimismo, la Corte dispuso que "Es indispensable que el Estado genere las condiciones y mecanismos óptimos para [que] dichos derechos políticos puedan ser ejercidos de forma efectiva, respetando el principio de igualdad y no discriminación". ${ }^{31}$

30 Corte IDH, Serie C núm. 127, Caso Yatama vs. Nicaragua, cit., párr. 201; Corte IDH, Serie C núm. 212, Caso Chitay Nech y otros vs. Guatemala. Sentencia del 25 de mayo de 2010. Excepción preliminar, fondo, reparaciones y costas, párr. 106.

31 Corte IDH, Serie C núm. 127, Caso Yatama vs. Nicaragua, cit., párr. 195; Corte IDH, Serie C núm. 184, Caso Castañeda Gutman vs. México, cit., párr. 145. 
Por otro lado, este caso también desarrolla que los derechos políticos no son absolutos, sino que aceptan las limitaciones de éstos, tal y como lo establece el artículo 23.2. Esto se hace en función del test de proporcionalidad, lo que significa que, para limitar los derechos políticos, los Estados deben observar los principios de legalidad, ${ }^{32}$ necesidad $^{33}$ y proporcionalidad $^{34}$ en una sociedad democrática. Por ende, se establece:

La restricción debe encontrarse prevista en una ley, no ser discriminatoria, basarse en criterios razonables, atender a un propósito útil y oportuno que la torne necesaria para satisfacer un interés público imperativo, y ser proporcional a ese objetivo. Cuando hay varias opciones para alcanzar ese fin, debe escogerse la que restrinja menos el derecho protegido y guarde mayor proporcionalidad con el propósito que se persigue. ${ }^{35}$

Teniendo en cuenta los temas desarrollados dentro del caso Yatama vs. Nicaragua, esta sentencia se ha visto incluida en los distintos espacios convencionales que se han creado a partir de la jurisprudencia de la Corte Interamericana, frente a las distintas disposiciones de los derechos políticos. Es así como, mediante la ayuda de la inteligencia artificial, se obtiene el grafo sobre la conexidad de las sentencias y la influencia de éstas a partir de la cantidad de conexiones.

32 En cuanto a la legalidad, la Corte Interamericana ha explicado que las condiciones y circunstancias generales que autorizan las limitaciones a un derecho humano deben estar claramente establecidas en la ley, entendida ésta tanto en su sentido formal como material (Corte IDH, 2017, párr. 119).

33 La necesidad se refiere a que la medida sea absolutamente indispensable para conseguir el fin deseado y que no exista una menos gravosa respecto al derecho intervenido entre todas aquellas que cuentan con la misma idoneidad para alcanzar el objetivo propuesto (Corte IDH, 2016, párr. 147).

34 La Corte Interamericana señala que debe analizarse si la limitación resulta estrictamente proporcional; para cumplir con ello, se debe determinar el grado de afectación de uno de los bienes en juego, la importancia de la satisfacción del bien contrario y si ésta se justifica en la limitación del otro (Corte IDH, 2008, párr. 84).

35 Corte IDH, Serie C núm. 127, Caso Yatama vs. Nicaragua, cit., párr. 206; Corte IDH, Serie C núm. 184, Caso Castañeda Gutman vs. México, cit., párrs. 174 y 185. 


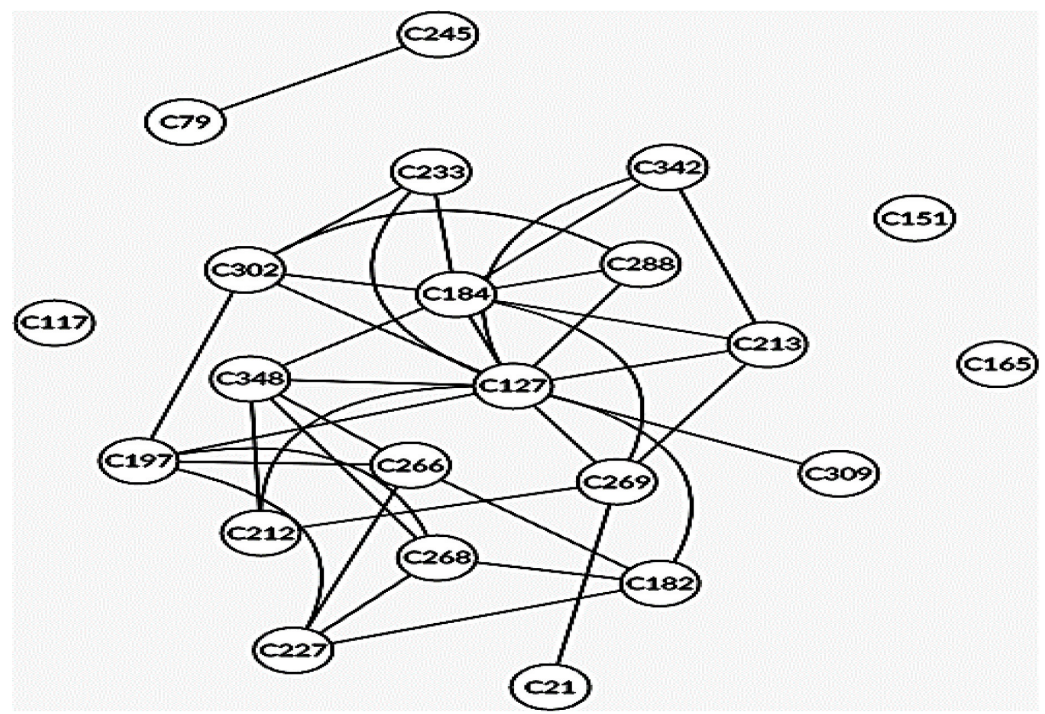

Este grafo evidencia el espacio citacional de los derechos políticos; además, permite identificar los cuatro "clústeres" de sentencias que se convierten en los espacios convencionales, de los cuales el usuario puede determinar los estándares que los Estados parte están obligados a respetar, garantizar y adecuar. Es por ello que dentro de los derechos políticos se encuentran cuatro espacios convencionales, los cuales son el derecho a decidir en asuntos públicos, el derecho a ser elegido, el derecho a elegir y las limitaciones a los derechos políticos.

\section{A. Derecho a ser elegido}

Dentro del grupo de sentencias en las cuales la Corte Interamericana se ha pronunciado sobre esta garantía a ser elegido, consagrada en el artículo 23 convencional, se encuentra el ya mencionado caso Yatama vs. Nicaragua, cuestión que es replicada por los casos Castañeda Gutman vs. México, Manuel Cepeda Vargas vs. Colombia, López Mendoza vs. Venezuela, Luna López vs. Honduras, Pacheco León y otros vs. Honduras y, por último, San Miguel Sosa y otras vs. Venezuela.

Inicialmente se analizará el caso Castañeda Gutman vs. México. Este asunto refiere a la responsabilidad internacional del Estado de México por la inexistencia de un recurso adecuado y efectivo en relación con el impedimento de Jorge Castañeda Gutman para inscribir su candidatura independiente a la 
Presidencia de México. ${ }^{36}$ En esta sentencia se encuentra el desarrollo del derecho a elegir y ser elegido, en donde se confirma lo expuesto por la Corte Interamericana en el casoYatama vs. Nicaragua y que en 2017 es reafirmado en la sentencia del caso Pacheco León y otros vs. Honduras.

...el artículo 23.1 de la Convención establece que todos los ciudadanos deben gozar de los siguientes derechos y oportunidades, los cuales deben ser garantizados por el Estado en condiciones de igualdad: i) a la participación en la dirección de los asuntos públicos, directamente o por representantes libremente elegidos; ii) a votar y a ser elegido en elecciones periódicas auténticas, realizadas por sufragio universal e igual y por voto secreto que garantice la libre expresión de los electores, y iii) a acceder a las funciones públicas de su país. ${ }^{37}$

De acuerdo con lo anterior, es importante destacar que todo ciudadano de los Estados parte de la Convención Americana tiene el derecho convencional a votar y a ser elegido en elecciones periódicas auténticas, realizadas por sufragio universal, en condiciones de igualdad y por voto secreto que garantice la libre expresión de los electores. Sin embargo, para proteger este derecho, la Corte Interamericana indica que los Estados no sólo tienen las obligaciones generales que establece el artículo 1o. de la Convención Americana, sino que además tienen obligaciones positivas:

El artículo 23 de la Convención Americana establece que sus titulares deben gozar de derechos políticos, pero, además, agrega el término "oportunidades", lo cual implica que los Estados deben garantizar con medidas positivas que toda persona que formalmente sea titular de derechos políticos tenga la oportunidad real para ejercerlos. Por lo tanto, es indispensable que el Estado genere las condiciones y mecanismos óptimos para que los derechos políticos puedan ser ejercidos de forma efectiva. La Corte señala, como lo ha hecho en otras ocasiones, que estas condiciones generales de igualdad están referidas tanto al acceso a la función pública por elección popular como por nombramiento o designación. ${ }^{38}$

36 Corte IDH, Serie C núm. 184, Caso Castañeda Gutman vs. México, cit.

37 Ibidem, párrs. 199 y 200; Corte IDH, Serie C núm. 233, Caso López Mendoza vs. Venezuela, cit., párr. 144; Corte IDH, Serie C núm. 348, Caso San Miguel Sosa y otras vs. Venezuela, cit., párr. 172.

38 Corte IDH, Serie C núm. 127, Caso Yatama vs. Nicaragua, cit., párr. 195; Corte IDH, Serie C núm. 184, Caso Castañeda Gutman vs. México, cit., párrs. 145 y 150; Corte IDH, Serie C núm. 
La Corte Interamericana establece que "el ejercicio efectivo de los derechos políticos constituye un fin en sí mismo y, a la vez, un medio fundamental que las sociedades democráticas tienen para garantizar los demás derechos humanos previstos en la Convención”. ${ }^{39}$ Debido a ello, la búsqueda de la participación política se garantiza de manera activa (elegido) o pasiva (elegir); asimismo, los Estados, en sus estatutos internos, deben crear normas para la efectiva participación de la sociedad, y con ella se cumpliría el objetivo de las sociedades democráticas. Para lograr este fin, uno de los mecanismos en los cuales la Corte Interamericana ha exhortado a los Estados es otorgando posibilidades reales de participación a la oposición. Frente a ello, dicho tribunal interamericano ha expresado:

...es de resaltar que las voces de oposición resultan imprescindibles para una sociedad democrática, sin las cuales no es posible el logro de acuerdos que atiendan a las diferentes visiones que prevalecen en una sociedad. Por ello, la participación efectiva de personas, grupos y organizaciones y partidos políticos de oposición en una sociedad democrática debe ser garantizada por los Estados, mediante normativas y prácticas adecuadas que posibiliten su acceso real y efectivo a los diferentes espacios deliberativos en términos igualitarios, pero también mediante la adopción de medidas necesarias para garantizar su pleno ejercicio, atendiendo la situación de vulnerabilidad en que se encuentran los integrantes de ciertos sectores o grupos sociales. ${ }^{40}$

La falta de garantías para la oposición por parte de los gobiernos generó dentro de la jurisprudencia de la Corte Interamericana un subespacio convencional frente a la protección del derecho a la vida (artículo 4o. convencional) y los derechos políticos (artículo 23 convencional). Dentro de este

213, Caso Manuel Cepeda Vargas vs. Colombia. Sentencia del 26 de mayo de 2010. Excepción preliminar, fondo, reparaciones y costas, párr. 172; Corte IDH, Serie C núm. 269, Caso Luna López vs. Honduras. Sentencia del 10 de octubre de 2013. Excepción preliminar, fondo, reparaciones y costas, párrs. 155 y 156; Corte IDH, Serie C núm. 342, Caso Pacheco León y otros vs. Honduras. Sentencia del 15 de noviembre de 2017. Excepción preliminar, fondo, reparaciones y costas, párr. 111.

39 Corte IDH, Serie C núm. 127, Caso Yatama vs. Nicaragua, cit., párr. 145; Corte IDH, Serie C núm. 184, Caso Castañeda Gutman vs. México, cit., párr. 108; Corte IDH, Serie C núm. 302, Caso López Lone y otros vs. Honduras. Sentencia del 5 de octubre de 2015. Excepción preliminar, fondo, reparaciones y costas, párr. 162.

40 Corte IDH, Serie C núm. 127, Caso Yatama vs. Nicaragua, cit., párr. 201; Corte IDH, Serie C núm. 213, Caso Manuel Cepeda Vargas vs. Colombia, cit., párr. 173. 
subespacio convencional, tenemos como caso insignia el de Manuel Cepeda Vargas vs. Colombia, el cual se refiere a la responsabilidad internacional del Estado por la ejecución extrajudicial de este senador integrante del partido político Unión Patriótica (opositor del gobierno de la época), así como la falta de investigación y sanción de los responsables. ${ }^{41}$ Por ende, frente a casos donde existe una interrelación de derechos, la Corte ha pronunciado lo siguiente:

Si bien cada uno de los derechos contenidos en la Convención tiene su ámbito, sentido y alcance propios, en ciertas ocasiones, por las circunstancias particulares del caso o por la necesaria interrelación que guardan, se hace necesario analizarlos en conjunto para dimensionar apropiadamente las posibles violaciones y sus consecuencias. ${ }^{42}$

De acuerdo con esto, la Corte Interamericana ha establecido que los Estados tienen obligaciones positivas frente a personas pertenecientes a la oposición para la protección de sus derechos políticos y el derecho a la vida; en especial, ellos tienen el deber de brindar protección a los miembros de los partidos políticos de oposición, que se encuentren en situaciones de riesgo. ${ }^{43}$

B. El derecho a la igualdad de oportunidades en el acceso y la estabilidad en cargos públicos

Otro estándar de protección dentro de la jurisprudencia de la Corte Interamericana, con respecto a los derechos políticos, es el derecho a la igualdad de oportunidades en el acceso y la estabilidad en cargos públicos. Este tema se ha desarrollado por parte de la Corte Interamericana en los casos de altos tribunales internos contra Estados, como Ecuador, Venezuela, entre otros. Es por ello que la Corte señala que las "condiciones generales de igualdad están referidas tanto al acceso a la función pública por elección popular como por nombramiento o designación". ${ }^{44}$

41 Corte IDH, Serie C núm. 213, Caso Manuel Cepeda Vargas vs. Colombia, cit.

42 Corte IDH, Serie C núm. 184, Caso Castañeda Gutman vs. México, cit., párr. 144; Corte IDH, Serie C núm. 213, Caso Manuel Cepeda Vargas vs. Colombia, cit., párr. 171.

43 Corte IDH, Serie C núm. 213, Caso Manuel Cepeda Vargas vs. Colombia, cit., párr. 100; Corte IDH, Serie C núm. 269, Caso Luna López vs. Honduras, cit., párr. 157.

44 Corte IDH, Serie C núm. 127, Caso Yatama vs. Nicaragua, cit., párr. 200; Corte IDH, Serie C núm. 182, Caso Apitz Barbera y otros ("Corte Primera de lo Contencioso Administrativo") vs. Vene- 
La Corte Interamericana, en casos como Apitz Barbera y otros ("Corte Primera de lo Contencioso Administrativo") vs.Venezuela y Reverón Trujillo vs. Venezuela, aclaró que el artículo 23.1.c no garantiza la vinculación, sino la igualdad en el acceso a los cargos de carácter público y mantenerse en ellos. ${ }^{45}$ Para cumplir con el fin de una igualdad real, se ha establecido que el respeto y garantía de este derecho se cumplen cuando "los criterios y procedimientos para el nombramiento, ascenso, suspensión y destitución sean razonables y objetivos", y que "las personas no sean objeto de discriminación en el ejercicio de este derecho". ${ }^{46}$ Frente a estos casos, respecto de la protección de los derechos políticos en los funcionarios judiciales, éstos deben contar con plena autonomía e independencia de cualquier injerencia de los gobiernos nacionales y los partidos políticos. Por lo tanto, se debe garantizar la igualdad de oportunidades en el acceso y la estabilidad en el cargo frente a toda injerencia o presión política.

\section{El derecho a participar en asuntos públicos}

Con relación al derecho de participación desde la esfera social, la Corte Interamericana ha emitido decisiones en dos tipos de casos: en los que se protegen el derecho al voto y también con respecto a los derechos de las comunidades indígenas y tribales interrelacionados con el derecho a participar en asuntos públicos, donde se encuentran el derecho a recibir información y el derecho de propiedad colectiva de las comunidades. La Corte Interamericana define, de manera general, al derecho de participación sobre asuntos públicos de la siguiente forma:

La participación política puede incluir amplias y diversas actividades que las personas realizan individualmente u organizadas, con el propósito de intervenir en la designación de quienes gobernarán un Estado o se encargarán de la dirección de

zuela. Sentencia del 5 de agosto de 2008. Excepción preliminar, fondo, reparaciones y costas, párr. 150 .

45 Corte IDH, Serie C núm. 177, Caso Kimel vs. Argentina. Sentencia del 2 de mayo de 2008. Fondo, reparaciones y costas; Corte IDH, Serie C núm. 268, Caso del Tribunal Constitucional (Camba Campos y otros) vs. Ecuador. Sentencia del 28 de agosto de 2013. Excepción preliminar, fondo, reparaciones y costas.

46 Corte IDH, Serie C núm. 177, Caso Kimel vs. Argentina, cit., párr. 206; Corte IDH, Serie C núm. 182, Caso Apitz Barbera y otros (“Corte Primera de lo Contencioso Administrativo") vs. Venezuela, cit., párr. 138; Corte IDH, Serie C núm. 233, Caso López Mendoza vs. Venezuela, cit., párr. 135. 
los asuntos públicos, así como influir en la formación de la política estatal a través de mecanismos de participación directa. ${ }^{47}$

Frente al derecho a elegir, se infieren los dos modelos de democracia o de participación ciudadana: la democracia representativa y la democracia participativa. En cuanto a la primera, se define como aquella que reside en la soberanía del pueblo y en la que las funciones a través de las cuales se ejerce el poder son desempeñadas por personas escogidas en elecciones libres y auténticas mediante el sufragio universal. ${ }^{48}$ Por su parte, la segunda se define como aquella en la que el pueblo ejerce de forma inmediata y directa a las funciones públicas. ${ }^{49}$ Es así como la Corte establece "el derecho de participar activamente en la dirección de los asuntos públicos directamente, mediante referendos, plebiscitos o consultas o bien, por medio de representantes libremente elegidos". ${ }^{50}$

En este sentido, la Corte Interamericana amplia el estándar de protección en relación con el derecho a la participación política, debido a que no sólo es una garantía de la persona que se presenta a un cargo, sino también el de la sociedad en general a elegir libremente a sus representantes. Por lo tanto, existe una obligación de los Estados de proveer medidas eficaces para garantizar la realización de procesos electorales adecuados y transparentes, ${ }^{51}$ con el fin de que los ciudadanos hagan control político y protejan, a su vez, uno de los fines esenciales de la Convención Americana: la protección de la democracia. ${ }^{52}$

47 Corte IDH, Serie C núm. 127, Caso Yatama vs. Nicaragua, cit., párr. 195; Corte IDH, Serie C núm. 233, Caso López Mendoza vs.Venezuela, cit., párr. 163.

48 Comisión Interamericana de Derechos Humanos, "Democracia y derechos humanos en Venezuela”, 2009, disponible en: http://www.cidh.org/countryrep/Venezuela2009sp/VE09CAPI SP.htm.

49 Massal, Julie, "Democracia participativa: desafíos y desencantos en el siglo XXI", Análisis Político, Colombia, vol. 23, núm. 69, 2010, pp. 79-91.

50 Corte IDH, Serie C núm. 182, Caso Apitz Barbera y otros ("Corte Primera de lo Contencioso Administrativo") vs.Venezuela, cit., párr. 147; Corte IDH, Serie C núm. 212, Caso Chitay Nech y otros vs. Guatemala, cit., párr. 107; Corte IDH, Serie C núm. 348, Caso San Miguel Sosa y otras vs. Venezuela, cit., párr. 111.

51 Corte IDH, Serie C núm. 177, Caso Kimel vs. Argentina, cit., párr. 158.

52 Corte IDH, Serie C núm. 127, Caso Yatama vs. Nicaragua, cit., párrs. 196 y 198; Corte IDH, Serie C núm. 288, Caso Argüelles y otros vs. Argentina. Sentencia del 20 de noviembre de 2014. Excepción preliminar, fondo, reparaciones y costas, párr. 221; Corte IDH, Serie C núm. 302, Caso López Lone y otros vs. Honduras, cit., párr. 221. 
El otro modelo es la democracia participativa, en donde la Corte Interamericana ha desarrollado el estándar frente a los derechos de la propiedad colectiva de las comunidades indígenas:

...frente a la utilización o explotación de recursos naturales en su territorio tradicional, el Estado debe, para efectos del presente caso, contar con mecanismos para garantizar la participación efectiva de los pueblos indígenas, a través de procedimientos culturalmente adecuados para la toma de decisiones de dichos pueblos. Lo anterior no solo consiste en un asunto de interés público, sino que también forma parte del ejercicio de su derecho a participar en la adopción de decisiones en las cuestiones que afectan sus intereses, de conformidad con sus propios procedimientos e instituciones, en relación con el artículo 23 de la Convención Americana. ${ }^{53}$

Para ello, la Corte Interamericana ha hecho uso del principio de integralidad, interpretando el artículo 7o. del Convenio 169 de la OIT para determinar que la consulta es el mecanismo más adecuado para la participación de las comunidades indígenas. ${ }^{54}$

Se puede concluir, entonces, que el derecho a participar en asuntos públicos se realiza mediante la participación directa de los ciudadanos o a través del voto, al cual tienen derecho todas las personas para elegir sus representantes. También se destaca la protección especial de acuerdo con las costumbres de los pueblos indígenas para la determinación de mecanismos de representación y participación respecto de los asuntos que afectan a sus territorios.

\section{Limitaciones a los derechos políticos}

La regla general es que los derechos humanos no se pueden limitar, restringir o suspender; empero, el parágrafo 2 del artículo 23 de la Convención Americana establece limitaciones a los derechos políticos, como son por razones de edad, nacionalidad, residencia, idioma, instrucción, capacidad civil

53 Corte IDH, Serie C núm. 127, Caso Yatama vs. Nicaragua, cit., párr. 225; Corte IDH, Serie C núm. 309, Caso Pueblos Kaliña y Lokono vs. Surinam. Sentencia del 25 de noviembre de 2015. Excepción preliminar, fondo, reparaciones y costas, párr. 203.

54 Organización Internacional del Trabajo (OIT), Convenio 169 sobre pueblos indígenas y tribales, 27 de junio de 1989, disponible en: https: / /www.ilo.org/wcmsp5/groups/public/--americas/--rolima/documents/publication/wcms_345065.pdf. 
o mental, o condena por juez competente en proceso penal. ${ }^{55}$ Frente a estas limitaciones, la Corte Interamericana se ha pronunciado en varias ocasiones, generando estándares para los Estados:

...es evidente que estas causales se refieren a las condiciones habilitantes que la ley puede imponer para ejercer los derechos políticos, y las restricciones basadas en esos criterios son comunes en las legislaciones electorales nacionales, que prevén el establecimiento de edades mínimas para votar y ser votado, ciertos vínculos con el distrito electoral donde se ejerce el derecho, entre otras regulaciones. Siempre que no sean desproporcionados o irrazonables, se trata de límites que legítimamente los Estados pueden establecer para regular el ejercicio y goce de los derechos políticos y que se refieren a ciertos requisitos que los titulares de los derechos políticos deben cumplir para poder ejercerlos. ${ }^{56}$

En este sentido, la Corte Interamericana impone un límite legislativo a los Estados frente a las restricciones de los derechos políticos, cuando establece que los Estados tiene legítima libertad de regular este derecho, siempre y cuando las limitaciones sean proporcionales, razonables y necesarias para el cumplimiento de un fin legítimo:

Ahora resta definir si aun cuando la medida sea legal y persiga un fin permitido por la Convención, ella es necesaria y proporcional. Con el fin de evaluar si la medida restrictiva bajo examen cumple con este último requisito, la Corte debe valorar si la misma: a) satisface una necesidad social imperiosa, esto es, está orientada a satisfacer un interés público imperativo; b) es la que restringe en menor grado el derecho protegido, y c) se ajusta estrechamente al logro del objetivo legítimo. ${ }^{57}$

Al respecto, existe un consenso regional en cuanto a la necesidad de restringir la participación de los jueces en las actividades político-partidistas, siendo que, en algunos Estados, de forma más general, se prohíbe cualquier participación en política, salvo la emisión del voto en las elecciones. Sin embargo, la facultad de los Estados de regular o restringir estos derechos no es discrecional y cualquier limitación a los

55 OEA, Convención Americana sobre Derechos Humanos, cit.

56 Corte IDH, Serie C núm. 127, Caso Yatama vs. Nicaragua, cit., párr. 155; Corte IDH, Serie C núm. 288, Caso Argüelles y otros vs. Argentina, cit., párr. 222.

57 Corte IDH, Serie C núm. 184, Caso Castañeda Gutman vs. México, cit., párr. 184; Corte IDH, Serie C núm. 302, Caso López Lone y otros vs. Honduras, cit., párr. 227. 
derechos consagrados en la Convención debe interpretarse de manera restrictiva. La restricción de participación en actividades de tipo partidista a los jueces no debe ser interpretada de manera amplia, de forma tal que impida que los jueces participen en cualquier discusión de índole política. ${ }^{58}$

En conclusión, los Estados tienen la libertad de limitar y/o restringir los derechos políticos, pero dentro de las facultades que están explícitas en la Convención Americana; asimismo, dichas limitaciones deben encontrarse en el marco de un juicio de proporcionalidad, que exige que la medida que restringe o limita el derecho corresponda al cumplimiento de un fin legítimo, además de ser necesaria y proporcional.

\section{CONCLUSIONES}

Con la aplicación de la inteligencia artificial creada por los grupos de investigación en derecho público de la Facultad de Derecho y "Acceder" de la Facultad de Ingeniería de la Universidad Militar Nueva Granada, se logró identificar, a partir de un total de 408 sentencias emitidas por la Corte Interamericana, 21 decisiones específicas relacionadas con los derechos políticos, lo que implica un avance significativo en términos de eficiencia en la búsqueda de las sentencias, porque no existió el desgaste de tomar otras decisiones que no tuvieran aplicación directa al derecho humano en estudio.

Asimismo, las sentencias seleccionadas se graficaron de acuerdo con la interactividad de sus citaciones, lo que permitió visualizar con mayor precisión los espacios citacionales, esto es, el grupo de sentencias que han decidido sobre el derecho, además de los niveles de relevancia de las sentencias que se consolidan a través del precedente, es decir, categoriza las sentencias respecto de los niveles de citación; con ello se establecen los estándares convencionales. Esto demuestra la efectividad sobre otros buscadores tradicionales que son utilizados por los usuarios de las sentencias de la Corte Interamericana, que reflejan decisiones que no directamente se relacionan con el derecho en estudio ni la consolidación de los presentes interamericanos.

58 Corte IDH, Serie C núm. 184, Caso Castañeda Gutman vs. México, cit., párr. 174; Corte IDH, Serie C núm. 288, Caso Argüelles y otros vs. Argentina, cit., párr. 172. 
Ahora bien, respecto de los derechos políticos, la herramienta arrojó el ranking sobre la sentencia más importante y la más citada, estableciendo que la sentencia del caso Yatama vs. Nicaragua era la de mayor citación y la más importante, siendo la sentencia fundadora de línea que describe de forma amplia las garantías de los derechos políticos, y la Corte Interamericana lleva quince años consolidando con este precedente sus estándares convencionales respecto de este derecho. Éstos se reflejaron en la herramienta con la creación de un grafo que ofrece información de conexidad y capacidad de influencia de las sentencias de los derechos políticos, permitiendo establecer los siguientes espacios convencionales: a) el derecho a ser elegido; b) el derecho a la igualdad de oportunidades en el acceso y la estabilidad en cargos públicos; c) el derecho a participar en asuntos públicos, y d) las limitaciones a los derechos políticos. Por lo tanto, se logró dar respuesta a la pregunta y cumplir con el objetivo de la investigación.

Además, la herramienta identificó conexiones de los derechos políticos con otros derechos convencionales, por ejemplo, el derecho a la libertad de pensamiento y expresión, el derecho a la vida y el derecho a la propiedad colectiva. Ello permite sugerir en la próxima versión del sistema semiautomático la posibilidad de generar espacios citacionales de segundo nivel, los cuales surgen de la interacción de dos o más derechos convencionales.

\section{BIBLIOGRAFÍA}

Benavides-Casals, María Angélica, "El efecto erga omnes de las sentencias de la Corte Interamericana de Derechos Humanos", International Law: Revista Colombiana de Derecho Internacional, Colombia, núm. 27, 2015.

BLACK, Henry, “The Principles of Stare Decisis”, University of Pennsylvania Law Review, Pensilvania, núm. 34.

Blasco Gascó, Francisco de Paula, "Funciones y eficacia de la norma jurisprudencial”, Estudios de Derecho Judicial, España, núm. 34, 2001.

CoHEN, Harlan Grant, "International Precedent and the Practice of International Law”, en Helfand, Michael A. (ed.), Negotiating State and Non-State Law: The Challenge of Global and Local Legal Pluralism, Cambridge University Press, 2015. 
Comisión Interamericana de Derechos Humanos, "Democracia y derechos humanos en Venezuela”, 2009, disponible en: http: //www.cidh.org/ countryrep / Venezuela2009sp/VE09CAPISP.htm.

FERNÁNDEZ FERNÁNDEZ, Vicente, "La justicia de los precedentes: ¿invasión a la independencia y autonomía del juzgador?”, Revista de Derecho (Valdivia), Chile, vol. 29, núm. 2.

García RamíreZ, Sergio, "El control judicial interno de convencionalidad", Revista IUS, Chile, vol. 5, núm. 28, 2011.

GARRIDO GÓMEZ, M. Isabel, "El valor de los precedentes judiciales en materia de igualdad", Anuario de la Facultad de Derecho (Universidad de Alcalá), España, núm. 4, 2011.

GonZÁlez, Andrés y SANABria, Jesús, "Obligaciones de los Estados parte de la Convención Americana”, Saber, Ciencia y Libertad, Colombia, vol. 8, núm. 2, 2013.

HitTers, Juan Carlos, “'Son vinculantes los pronunciamientos de la Comisión y de la Corte Interamericana de Derechos Humanos? (control de constitucionalidad y convencionalidad)", Revista Iberoamericana de Derecho Procesal Constitucional, México, vol. 10, 2008.

JimÉNEZ DE ARÉCHAGA, Eduardo et al., Derecho internacional público: principios, normas y estructuras, Montevideo, Fundación de la Cultura Universitaria, 2005, t. 1.

LEgarRe, Santiago y Rivera, Julio César, "Naturaleza y dimensiones del «stare decisis»”, Revista Chilena de Derecho, Chile, vol. 33, núm. 1, 2006.

LÓPEZ MEDINA, Diego, El derecho de los jueces: obligatoriedad del precedente constitucional, análisis de sentencias y líneas jurisprudenciales y teoría del derecho judicial, 2a. ed., Bogotá, Legis, 2006.

MASSAL, Julie, "Democracia participativa: desafíos y desencantos en el siglo XXI”, Análisis Político, Colombia, vol. 23, núm. 69, 2010.

NOGUERA LABORDE, Rodrigo, Introducción general al derecho, Bogotá, Universidad Sergio Arboleda, 2015.

Pérez Perdomo, Rogelio, “González Martín, Nuria, Sistemas jurídicos contemporáneos, México, Nostra Ediciones-UNAM, Instituto de Investigaciones Jurídicas, 2010”, Boletín Mexicano de Derecho Comparado, México, vol. XLVI, núm. 136, 2013.

QuinCHE, Manuel, El precedente judicial y sus reglas, 2a. ed., Bogotá, Ediciones Doctrina y Ley, 2016. 
Toro Huerta, Mauricio Iván del, "Anatomía del precedente internacional (esbozo para la discusión)”, en CARbonell SÁnchez, Miguel et al. (coords.), Estado constitucional, derechos humanos, justicia y vida universitaria. Estudios en homenaje a Jorge Carpizo, México, UNAM, Instituto de Investigaciones Jurídicas, 2015, t. III.

ToTH, Adryan J. W., "Clarifying the Role of Precedent and the Doctrine of Stare Decisis in Trial and Intermediate Appellate Level Charter Analysis", Dalhousie Journal of Legal Studies, vol. 22, 2013.

WhitTAKer, Simon y BANFi DEL Río, Cristian, "El precedente en el derecho inglés: una visión desde la ciudadela”, Revista Chilena de Derecho, Chile, vol. 35, núm. 1, 2008. 